\title{
Preparation and characterization of graphite/thermosetting composites
}

\author{
JIE CHEN ${ }^{1}$, QI-ZHONG ZHANG ${ }^{1}$, ZHE-SHENG HOU ${ }^{2}$, FAN-LONG JIN ${ }^{1}$ and SOO-JIN PARK ${ }^{3, *}$ \\ ${ }^{1}$ Department of Polymer Materials, Jilin Institute of Chemical Technology, Jilin City 132022, People's Republic of China \\ ${ }^{2}$ School of Mechanical and Electrical Engineering, Jilin Institute of Chemical Technology, Jilin City 132022, \\ People's Republic of China \\ ${ }^{3}$ Department of Chemistry, Inha University, Nam-Gu, Incheon 402-751, Korea \\ *Author for correspondence (sjpark@inha.ac.kr)
}

MS received 22 June 2018; accepted 1 January 2019; published online 13 May 2019

\begin{abstract}
Graphite/thermosetting composites were prepared via a melt blending and compression-curing process using epoxy and phenolic resins as polymer matrices. The flexural strength, flexural modulus and electrical conductivity of the composites were investigated. The composites containing $55 \mathrm{wt} \%$ graphite showed the maximum flexural strength and modulus. Scanning electron microscopy results showed that the thermosetting resins and graphite were uniformly dispersed on the fractured surface of the composites. The electrical conductivity of the composites increased with an increase in the graphite content. The flexural and electrical properties of the composites improved significantly by the addition of a carbon fibre cloth (CFC) or a CFC and carbon nanotubes.
\end{abstract}

Keywords. Graphite; carbon fibres; mechanical properties; electrical conductivity; carbon nanotubes.

\section{Introduction}

Grounding grids of power systems are used to eliminate the charge accumulated in electrical equipment. Such grids are buried directly into the ground and are usually built using metals. However, electrochemical corrosion can degrade grounding grids. The corrosion products formed on the surface of grounding grids affect their conductivity. The complete corrosion of grounding grids decreases their power supply capacity, thus endangering the safe operation of the equipment [1-4].

In China, flat steel is extensively used for grounding grids. Steel is cheaper and shows better thermal stability than copper. However, its corrosion resistance is poor. Galvanized steel has been used to improve the corrosion resistance of grounding grids. However, the galvanized layer becomes corroded in soil. Hence, the development of corrosion-resistant grounding grids is challenging [5-8].

Graphite has a layered structure with each carbon atom attached to three other carbon atoms by covalent bonds with the layers held together by van der Waals forces. Because each carbon atom in graphite emits a delocalized $\pi$ electron which can move freely in the direction of the plane, graphite shows good electrical and thermal conductivities. Additionally, graphite shows excellent corrosion and thermal shock resistances. Therefore, graphite-based materials are widely used in conductive materials, microwave absorbing materials, electromagnetic shielding materials and antistatic materials $[9,10]$.
Conventional sintering and compression sintering are the synthesis methods for graphite materials. Moulding involves the following steps: carbon powders or graphite powders and graphitized resin are mixed, moulded and graphitized at high temperature under a reducing atmosphere or vacuum. This method has some disadvantages such as high process temperature, energy consumption and cost [11].

Recently, in situ synthesis methods have been used for the preparation of graphite/thermosetting composites. In these methods, one or several reinforcements are formed in the matrix through in situ polymerization for strengthening the composites [12]. Among various thermosetting resins, epoxy and phenolic resins are widely used as polymer matrices for the preparation of conductive composites because of their excellent mechanical properties, thermal stability and solvent resistance. Epoxy and phenolic resins also have a high interface with graphite $[13,14]$. The resulting composites show corrosion resistance similar to that of graphite. Although the polymer resin content of these composites is low, they maintain the processability of polymers and can be moulded by typical polymer processing techniques such as extrusion, moulding and injection moulding. Therefore, graphite/thermosetting composites can be easily prepared on a large scale, and the production cost of the composites can be greatly reduced by one-time moulding [15].

In this study, graphite/thermosetting composites were prepared using epoxy and phenolic resins as polymer matrices via a melt blending and compression-curing process. The effect of the graphite content on the flexural strength, 
flexural modulus and electrical properties of the composites was investigated. The effects of different fillers on the mechanical and electrical properties of the composites were also investigated.

\section{Experimental}

Diglycidylether of bisphenol A (E-51) (epoxide equivalent weight of 185-208 g per equivalent, Feicheng Deyuan Chemical Co. Ltd, China) was used as the epoxy resin in this study. The thermally latent initiator $N$-benzylpyrazinium hexafluoroantimonate (BPH) was synthesized using a method reported elsewhere [16]. Phenolic resin was prepared using a method reported previously. Graphite with a carbon content of 90\% was supplied by Jilin Graphite Industry Co., China. The carbon fibre powders and carbon fibre cloth (CFC, K12, bidirectional fibres) were supplied by Jilin Jiyan High-Tech Fibers Co. Ltd. The diameter and length of the carbon fibre powders were 7 and 10-70 mm, respectively. Hydroxyl-functionalized multiwall carbon nanotubes (CNTs) with a diameter of 20-30 nm, length of $10-30 \mu \mathrm{m}$ and $\mathrm{OH}$ content of $1.76 \mathrm{wt} \%$ (MH5 111216) were supplied by Chengdu Organic Chemicals Co. Ltd. of the Chinese Academy of Sciences.

Phenol (112.9g, $1.2 \mathrm{~mol}), 37 \%$ formaldehyde $(121.7 \mathrm{~g}$, $1.5 \mathrm{~mol})$ and ammonia $(2.1 \mathrm{~g}, 0.06 \mathrm{~mol})$ were added to a $500 \mathrm{ml}$ four-necked round-bottomed flask equipped with a mechanical stirrer, thermometer sensor and reflux condenser. The mixture was heated slowly to $100^{\circ} \mathrm{C}$ and reacted for $2 \mathrm{~h}$. The unreacted substance and water were removed by distillation at $80^{\circ} \mathrm{C}$ under vacuum. The phenolic resin was obtained as a viscous liquid (yield: $94 \%$ ).

The DGEBA/phenolic resin ratio of the thermosetting resin was $50 / 50 \mathrm{wt} \% / \mathrm{wt} \%$. The graphite content of the graphite/thermosetting composites was varied from 50 to $75 \mathrm{wt} \%$. The graphite/thermosetting composites were prepared by a melt blending and compression-curing process. The desired amounts of DGEBA, phenolic resin, graphite and $\mathrm{BPH}$ were mixed in a mixer at $80^{\circ} \mathrm{C}$ for $1 \mathrm{~h}$. The resulting mixture was injected into a preheated mould. The mould was compression-cured at temperatures ranging from 100 to $140^{\circ} \mathrm{C}$ and a pressure of $13.5 \mathrm{MPa}$ for $3 \mathrm{~h}$.

Graphite/thermosetting/CFC laminates were prepared as follows: the desired amounts of DGEBA, phenolic resin, graphite and $\mathrm{BPH}$ were mixed in a mixer at $80^{\circ} \mathrm{C}$ for $1 \mathrm{~h}$. The mixture was injected into a preheated mould in which a specific amount of CFC was placed. The mould was compression-cured over the temperature range of $100-140^{\circ} \mathrm{C}$ at a pressure of $13.5 \mathrm{MPa}$ for $3 \mathrm{~h}$. The resulting laminates were sandwich-shaped and are shown in figure 1.

Flexural testing was performed using a three-point bending test according to the GB/T13465.2-92 standard. The specimen size was $10 \times 10 \times 64 \mathrm{~mm}^{3}$.

The resistivity of the composites was measured at room temperature using a DC resistance tester (AST10A) according

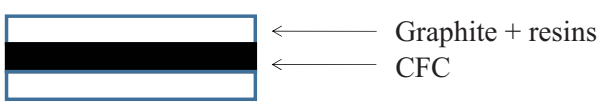

Figure 1. Structure of CFC/graphite/thermosetting laminates.

to the GB/T 24525-2009 standard. The sample size was $5 \times$ $50 \times 50 \mathrm{~mm}^{3}$.

The morphologies of the composites were investigated using field emission scanning electron microscopy (S-8000/ Hitachi).

\section{Results and discussion}

The graphite/thermosetting composites were manufactured via a melt blending and compression-curing process. The mechanical properties of the composites were evaluated by determining their flexural strength and elastic modulus. The values of the flexural strength and elastic modulus were calculated using the following equations $[17,18]$ :

$$
\begin{aligned}
F & =\frac{3 P L}{2 b d^{2}}, \\
E_{\mathrm{b}} & =\frac{L^{3}}{4 b d^{3}} \frac{\Delta p}{\Delta m},
\end{aligned}
$$

where $F$ is the flexural strength, $E_{\mathrm{b}}$ the elastic modulus, $P$ the applied load, $L$ the span length, $b$ the width of the specimen, $d$ the thickness of the specimen, $\Delta P$ is the change in force in the linear portion of the load-deflection curve and $\Delta m$ is the corresponding change in the deflection.

Figure 2 shows the flexural strength of the graphite/thermosetting composites as a function of the graphite content. The flexural strength of the neat resin system was $90.5 \mathrm{MPa}$,

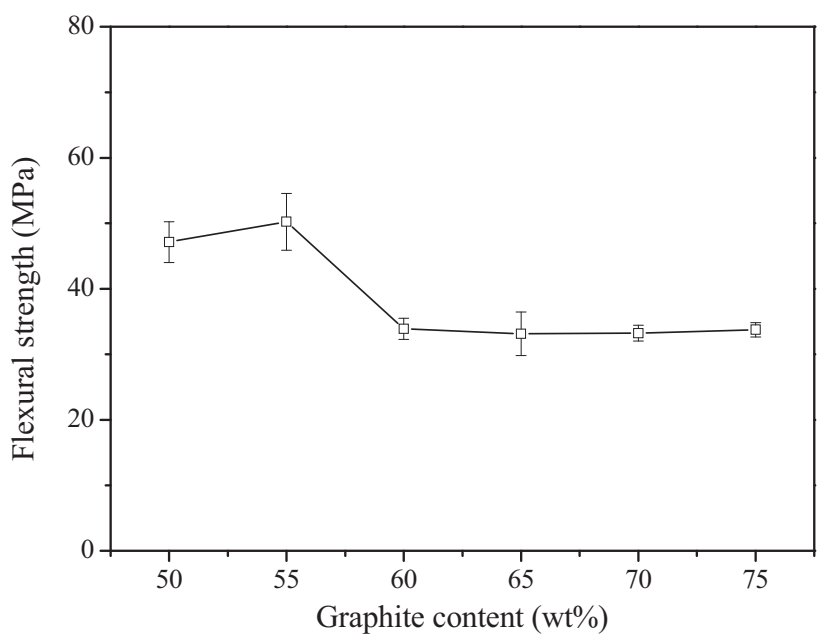

Figure 2. Flexural strength of graphite/thermosetting composites as a function of graphite content. 


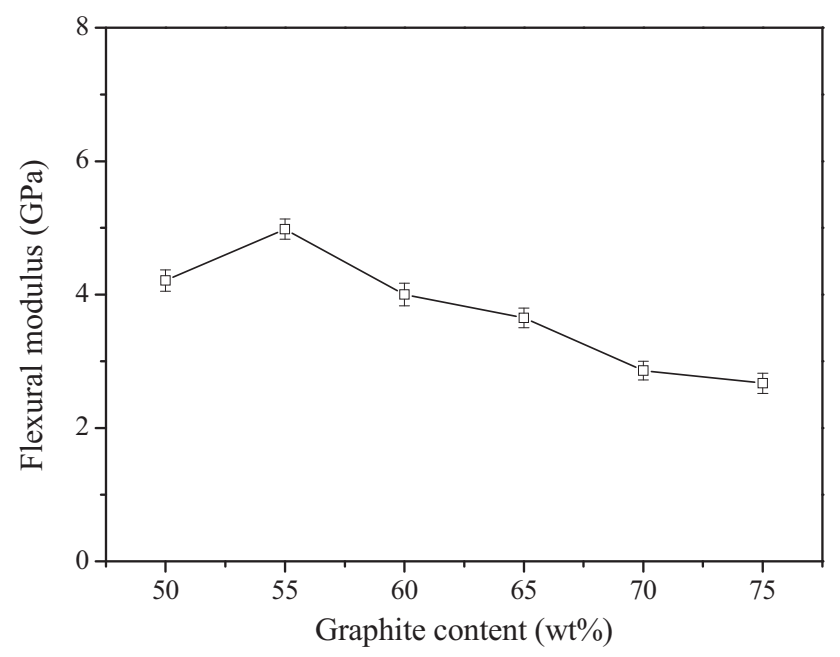

Figure 3. Flexural modulus of graphite/thermosetting composites as a function of graphite content.

whereas the flexural strength of the graphite/thermosetting composite containing $50 \mathrm{wt} \%$ graphite was $47.2 \mathrm{MPa}$, which was $48 \%$ lower than that of the neat resin system. The flexural strength of the composites increased as the graphite content was increased from 50 to $55 \mathrm{wt} \%$ and was the highest for the composite containing $55 \mathrm{wt} \%$ graphite. At the graphite content of $60-75 \mathrm{wt} \%$, the flexural strength of the composites remained constant $[19,20]$. Thus, $75 \mathrm{wt} \%$ was chosen as the optimum graphite content for the preparation of the graphite/thermosetting composites using various fillers.

Figure 3 shows the relationship between the flexural modulus and graphite content of the graphite/thermosetting composites. The flexural modulus of the composites first increased with an increase in the graphite content (up to $55 \mathrm{wt} \%)$ and then decreased.

Following the flexural strength tests of the composites, their morphology was investigated using SEM. Figure 4 shows the SEM image of the composites after the flexural strength tests. The thermosetting resins (epoxy and phenolic resins) and graphite are uniformly dispersed on the fractured surface of the graphite/thermosetting composites [21,22].

The electrical properties of the graphite/thermosetting composites were evaluated by determining their electrical conductivity. The electrical conductivity was calculated as follows $[23,24]$ :

$$
\sigma=\frac{1}{\rho}=\frac{I \cdot L}{U \cdot S}
$$

where $\sigma$ is the conductivity, $\rho$ the resistivity, $I$ the applied current, $L$ the thickness of the sample, $U$ the voltage through the sample and $S$ the cross-sectional area of the sample.

Figure 5 shows the electrical properties of the graphite/ thermosetting composites as a function of the graphite

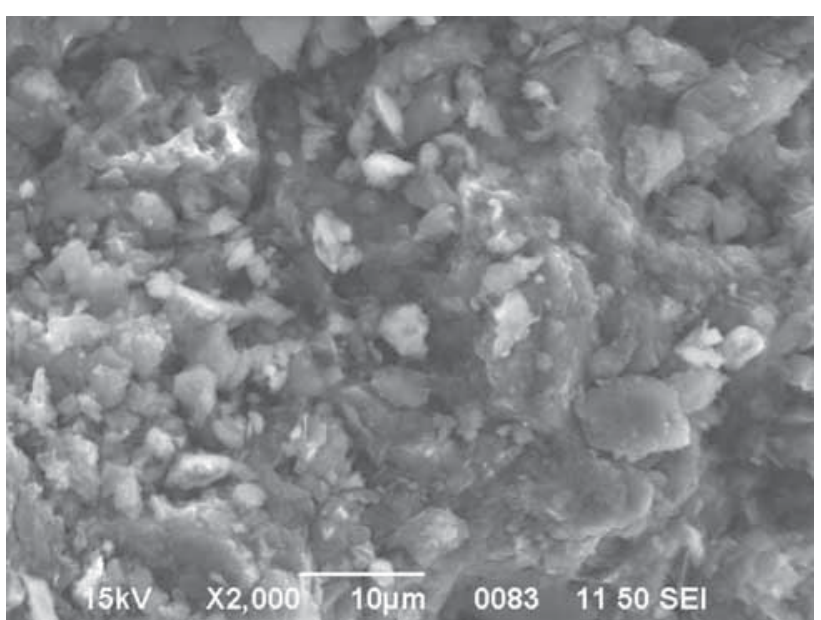

Figure 4. SEM image of graphite/thermosetting composites after flexural strength.

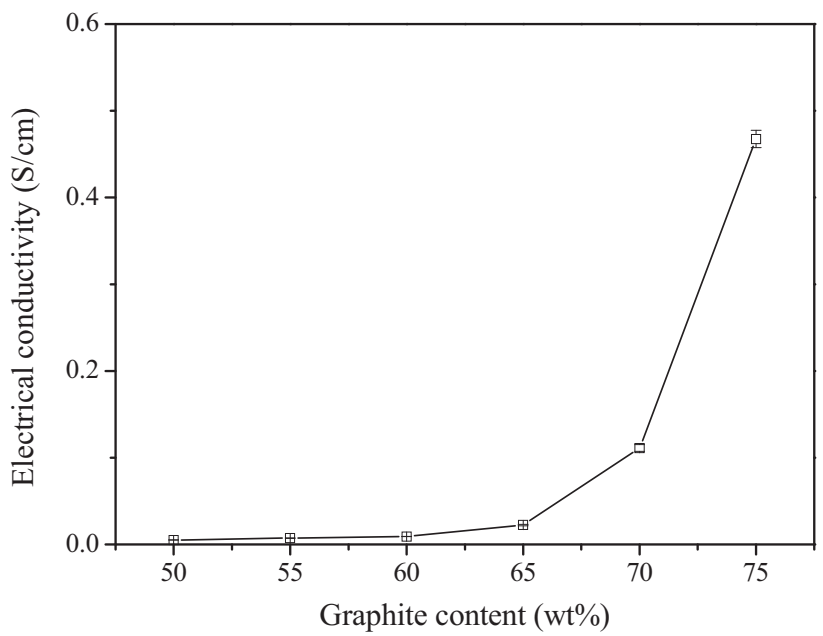

Figure 5. Electrical properties of graphite/thermosetting composites as a function of graphite content.

content. The electrical conductivity of the composites increased with an increase in the graphite content. At graphite contents higher than $65 \mathrm{wt} \%$, the electrical conductivity of the composites increased significantly because of the good electrical conductivity of graphite [14,25].

Table 1 shows the flexural and electrical properties of the graphite/thermosetting composites prepared using various fillers. The flexural strength and flexural modulus of the composites increase slightly with the addition of the carbon fibre powders. The flexural strength and flexural modulus of the laminates improve by the addition of CFC or CFC and CNTs. These results can be attributed to the good interfacial adhesion between the CFC and the thermosetting resin formed by the reaction between the epoxy resin on the surface of the CFCs and the thermosetting matrix. This interfacial adhesion facilitated a load transfer 
Table 1. Flexural and electrical properties of graphite/thermosetting composites with various fillers.

\begin{tabular}{|c|c|c|c|c|}
\hline No. & Filler & Flexural strength $(\mathrm{MPa})$ & Flexural modulus (GPa) & Electrical resistivity $\left(\mathrm{S} \mathrm{cm}^{-1}\right)$ \\
\hline 1 & - & $34.74 \pm 1.12$ & $2.67 \pm 0.15$ & $0.47 \pm 0.01$ \\
\hline 2 & $1 \mathrm{wt} \%$ carbon fibre powders & $35.38 \pm 1.29$ & $2.80 \pm 0.04$ & $25.97 \pm 0.67$ \\
\hline 3 & 1 layer CFC & $41.69 \pm 1.32$ & $3.00 \pm 0.02$ & $33.33 \pm 0.89$ \\
\hline 4 & 1 layer $\mathrm{CFC}+0.5 \mathrm{wt} \% \mathrm{CNTs}$ & $41.13 \pm 1.42$ & $3.19 \pm 0.02$ & $48.41 \pm 1.43$ \\
\hline
\end{tabular}

Graphite content, 75 wt\%; CFC, carbon fibre cloth; CNTs, carbon nanotubes.

from the matrix to the $\mathrm{CFC}$, thus, efficiently absorbing the external energy to increase the flexural strength of the composites [26-29].

The electrical conductivity of the graphite/thermosetting composites increased significantly with the addition of the carbon fibre powders. A further increase was observed by the addition of CFC or CFC and CNTs. These results can be attributed to the high electrical conductivities of CFC $\left(10^{3} \mathrm{~S} \mathrm{~cm}^{-1}\right)$ and CNTs $\left(10^{4} \mathrm{~S} \mathrm{~cm}^{-1}\right)$ [30-33].

\section{Conclusions}

Graphite/thermosetting composites were prepared using a melt blending and compression-curing process and their mechanical and electrical properties were evaluated by measuring their flexural strength and flexural modulus and electrical conductivity, respectively. The composite with $55 \mathrm{wt} \%$ graphite showed the maximum flexural strength and flexural modulus of the composites. The flexural strength of the composites remained constant at the graphite contents of $>60 \mathrm{wt} \%$. The SEM result showed that the epoxy and phenolic resins and graphite were uniformly dispersed on the fractured surface of the graphite/thermosetting composites. The electrical conductivity of the composites increased with an increase in the graphite content from 50 to $65 \mathrm{wt} \%$. The electrical conductivity of the composite increased significantly with an increase in the graphite content beyond $65 \mathrm{wt} \%$. The flexural and electrical properties of the composites improved significantly by the addition of CFC or CFC and CNTs.

\section{References}

[1] Kostić V I and Raičević N B 2016 Electr. Power Syst. Res. 131 31

[2] Visacro S, Guimarães M B and Araujo L S 2013 Electr. Power Syst. Res. 9492

[3] Li C, He W, Yao D, Yang F, Kou X and Wang X 2014 Int. J. Electr. Power Energy Syst. 63158

[4] Oliveira R M S, Modesto J F M, Maia M R V, Fujiyoshi D M and Raizer A 2014 J. Electrost. 72372
[5] Mohammadpour M, Yazdian N, Yang G, Wang H P, Carlson B and Kovacevi R 2018 Opt. Laser Technol. 98214

[6] Colombo A, Oldani L and Trasatti S P 2018 Eng. Fail. Anal. 84 46

[7] Mohammadpour M, Yazdian N, Wang H P, Carlson B and Kovacevic R 2018 J. Manuf. Process. 3120

[8] Lin H C, Hsu C A, Lee C S, Kuo T Y and Jeng S L 2018 J. Mater. Process. Technol. 251205

[9] Ramanujam B T S, Radhakrishnan S and Deshpande S D 2017 Macromol. Res. 25311

[10] Park G D, Jung H O, Kim K M, Lim J H, Lee J W, Lee S G et al 2015 Macromol. Res. 23396

[11] Lin S, Anwer M A S, Zhou Y, Sinha A, Carson L and Naguib H E 2018 Compos. B 13261

[12] Wei P, Cui S and Ba S 2017 Compos. Sci. Technol. 153151

[13] Lin H, Lu W and Chen G 2007 Physica B 400229

[14] Zhang X, Shen L, Xia X, Wang H and Du Q 2008 Mater. Chem. Phys. 111368

[15] Zaghloul M M Y, Zaghloul M Y M and Zaghloul M M Y 2017 Polym. Test. 63467

[16] Chen J L, Jin F L and Park S J 2010 Macromol. Res. 18862

[17] Jin F L, Ma C J and Park S J 2011 Mater. Sci. Eng. A 5288517

[18] Jin F L and Park S J 2006 J. Polym. Sci. Polym. Phys. 443348

[19] Sykam N, Gautam R K and Kar K K 2015 Polym. Eng. Sci. 55 917

[20] Kang S J, Kim D O, Lee J H, Lee P C, Lee M H, Lee Y et al 2010 J. Power Sources 1953794

[21] Al-Ghamdi A A, Al-Hartomy O A, Al-Solamy F, Al-Ghamdi A A and El-Tantawy F 2013 J. Appl. Polym. Sci. 1272227

[22] Fan Z, Zheng C, Wei T, Zhang Y and Luo G 2009 Polym. Eng. Sci. 492041

[23] Li W, Jing S, Wang S, Wang C and Xie X 2016 Int. J. Hydrogen Energy 4116240

[24] Choi M H, Jeon B H and Chung I J 2000 Polymer 413243

[25] Zheng C, Fan Z, Wei T and Luo G 2009 J. Appl. Polym. Sci. 113 1515

[26] Park S J and Jang Y S 2001 J. Colloid Interface Sci. 23791

[27] Dong W, Liu H C, Park S J and Jin F L 2014 J. Ind. Eng. Chem. 201220

[28] Zhao F and Huang Y 2010 Mater. Lett. 642742

[29] Park S J, Kim M H, Lee J R and Choi S 2007 J. Colloid Interface Sci. 228287

[30] Jin F L and Park S J 2013 Carbon Lett. 141

[31] Tsotra P and Friedrich K 2003 Compos. A 3475

[32] Jin F L and Park S J 2011 Carbon Lett. 1257

[33] Chaiwan P and Pumchusak J 2015 Electrochim. Acta 1581 